\title{
Feasibility of Direct Current Street Lighting \& Integrated Electric Vehicle Charging Points
}

\author{
K. A. Smith, S. J. Galloway, A. Emhemed and G. M. Burt \\ University of Strathclyde, Glasgow,U.K, \{contact: kyle.smith@strath.ac.uk\}
}

Keywords: Electric vehicles, charging, street lighting, direct current distribution networks.

Abstract: The application of Low Voltage Direct Current (LVDC) distribution systems have the potential to offer several advantages over the incumbent AC networks. LVDC systems are technically and economically viable in niche applications such as data centres and marine power systems, however they also have the potential to offer improvements in the power transfer capability of existing distribution cable assets, with the added advantage of enhanced controllability and reduced losses [1]. The application of LVDC in this field is still in a nascent stage of development and it is far from a business as usual solution for the Distribution Network Operators (DNOs). There is a lack of experience with installation, the commercial arrangements are not in place, and the standards necessary to configure, operate, and protect such new systems have yet to emerge. Proponents of DC distribution have previously conceptualised the integration of EV charging into future DC street lighting networks [2] and prototype AC charging units that conveniently attach to lighting columns are currently being tested [3],[4]. However, no literature examines the technical implementation of multiple EV charging units onto lighting networks with respect to existing cable specifications, protection and voltage drop standards. This paper demonstrates the viability of such systems and the performance advantages that DC distribution offers compared to $\mathrm{AC}$ in this integrated application.

\section{Introduction}

The move towards increased electrification of heat and transport has put traditional distribution systems under pressure due to significant increases in bulk power flows and changes to daily demand profiles. However, some existing assets such as street lighting cables are not fully utilised, considering power flows occur for only 8-14 hours a day depending on the season. Furthermore, many lighting cables have maximum current and voltage ratings of 60-100A and are insulated to a $0.6 \mathrm{kV} / 1 \mathrm{kV}$ AC (core to ground/core to core) standard [5], which is sufficient to support AC power flows of up to $14-23 \mathrm{~kW}$ and even higher power flows under a DC distribution regime.

There are approximately 6 million street lighting columns in the UK with an estimated $10 \%$ converted to LED lighting modules that are generally $50-80 \%$ more efficient than the traditional lighting solutions [6] and are natively DC powered. Currently there are nearly 4000 public electric vehicle charging locations in the UK and it is estimated that, in order to support an electric transportation system, the UK will require a mix of public, domestic and work place charging points with a ratio of one public charging point to ten EVs on the road [7] [8]. The UK strategy for low emission vehicles promotes charging at home during the lower nighttime power demand [9] however, approximately $35 \%$ of UK households do not have off-street parking facilities, this equates to a total of 9.2 million households that may require curb side, public night-time charging points [10]. By integrating the role-out of LED street lighting systems and EV charging points on lighting networks; new cable installation costs could be avoided and combined operational efficiencies may be achieved, while helping the UK meet its EV infrastructure targets [4].

Research in [1] and [11] demonstrates the higher power transfer capability of DC distribution using existing cable assets while Direct Current B.V. has successfully installed a new DC street lighting network in the Netherlands which claims higher energy efficiency and lower installation costs compared to AC due to a simplified LED driver and reduced cross-sectional area of the cables [2]. In addition, small-scale pilot projects have trialled the use of AC charging systems on lighting networks but questions remain on the ability of these systems to meet future power demand from EVs, the metering arrangements and technical acceptance from DNOs [4]. This paper assesses the integration of multiple EV charging points on existing street lighting networks and proposes a DC distribution solution that offers greater flexibility in positioning charging points on the lighting network with higher power distribution levels. This DC distribution regime increases the daily energy available for charging EV batteries and therefore allows more vehicles to be charged over a 24 hour period compared to AC distribution.

In Section 2, the most common street lighting network arrangements are discussed and the feasibility of integrating existing $\mathrm{AC}$ electric vehicle charging points onto the network is presented in Section 3. In Section 4, a DC distribution system is proposed that takes into consideration the existing cable specifications, protection schemes and overall system efficiency. The DC charging standards are reviewed and the physical implementation of this solution is discussed.

\section{Street Lighting Network Design}

Street lighting network design and specifications can vary depending on the standards set by the Local Authority (LA) and the environment in which the lighting system is operating. The cable cross-section diameter, number of cores, 
lighting column spacing and height of lighting columns will influence the performance of both AC and DC systems. The electrical supply to street side furniture is designed and installed according to BS7671 Requirements for Electrical Installations and BS7430 Code of Practice for Protective Earthing of Electrical Installations [12]. The local District Network Operator (DNO) can provide a power supply to the lighting network in two ways [13]. These are summarised in the following subsections.

\subsection{Feeder to Lighting Cabinet}

In Fig. 1, configuration (a) involves a 3-phase supply to a lighting cabinet at which point the LA or private developer takes ownership of the lighting network. This could be considered the most practical configuration for further investigation as it offers the highest power delivery compared to the 'direct column' supply.

\subsection{Direct Column Supply}

The direct column supply approach in (b) provides a $4 \mathrm{~mm}^{2}$ copper cable off a main service feeder, this permits a maximum continuous power supply of $2 \mathrm{kVA}$ which is not of a sufficient power rating for even the smallest AC charging solutions. However, this supply cable could be replaced with a larger rating, to enable specific lighting columns for AC charging.

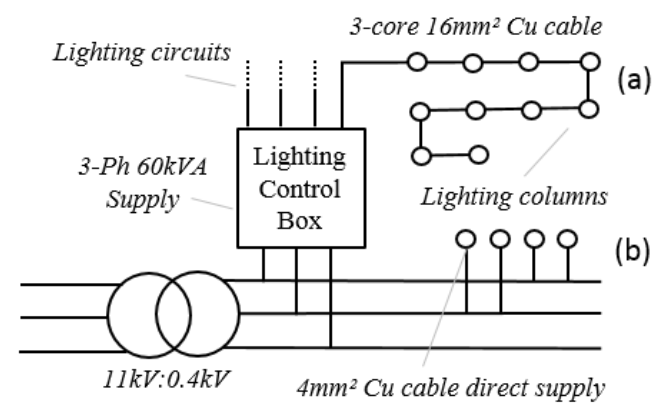

Fig. 1: DNO supply options for lighting circuits: 3-ph 60kVA supply to lighting control cabinet (a), direct column lighting (b).

\subsection{Lighting Control}

The majority of street lighting networks in the U.K. are currently unmetered due to their predictable energy consumption and low billing rates [14]. The LA receives a bill from the energy supplier which is based on a fixed power demand assessment and expected number of operational hours. The introduction of other services to these networks (e.g. electric vehicle charging points on the lighting network) would therefore require additional metering to be installed as well as commercial arrangements with both the DNO and LA energy supplier. Many LA's are transitioning towards 'smarter', controlled LED solutions for street lighting networks [6] so, in conjunction with this, the introduction of remote monitoring and metering equipment could be considered.
Currently, there are many novel ancillary applications that are under consideration for future street lighting networks, these include independent column sensors to detect movement on the street and sequentially increase illumination in the direction of pedestrian or vehicle travel [6], [15]. Further controls such as environmental sensors, Close Circuit Television and wireless internet hubs have been trialled on lighting networks that has led to lighting columns becoming the 'smart nodes' of future cities [16]. These new service developments open the opportunity for the integration of EV charging and the potential of a collaborative control system for the network. The following section provides more detail on the existing EV charging solutions that could be integrated into street lighting networks and their effect on power quality.

\section{AC Lighting Network \& EV Charging}

This section considers the technical feasibility of integrating $\mathrm{AC}$ charging points onto the existing street lighting networks as a baseline comparison for the DC system. The potential of this AC charging application is evaluated with respect to voltage drops, network protection and system energy efficiency in order to determine the maximum power delivery and number of chargers the network can accommodate while remaining within regulatory standards.

\subsection{Voltage Drops}

The implementation of $\mathrm{AC}$ charging points on the lighting network presented in Fig. 1 would require minimal modifications. Pilot projects have utilised an in-column charger that can be mounted within existing columns and directly connected to the network [4]. In some areas lighting columns are set back from the curbside and therefore a cutout and cable extension to the curbside charging pillar would be required. However, the positioning of charging points along the network is dictated by the allowable voltage drop from the lighting control box which is influenced by the charger rating, cable size and assumed power factor. Fig. 2 illustrates the transferable power distance while remaining within a voltage drop limitation of $3 \%$ as specified in BS7671 for public lighting systems. It is assumed that the lighting network cable is a 3 -core, copper, $0.6 / 1 \mathrm{kV}$, XLPE, armoured with a sustained current rating of $91 \mathrm{~A}$ in direct ground burial and a voltage drop of $2.8 \mathrm{mV} / \mathrm{A} / \mathrm{m}$ as specified by cable charts in BS7671 [17]. The cable voltage drop specification reflects the total cable circuit voltage drop per unit length.

The maximum distance that an $\mathrm{AC}$ charging point can be located from the lighting control box can be determined by first assessing the available voltage drop on the lighting network with only the expected lighting load. If all lighting columns are separated by the same distance and possess the same lighting power, this is given by:

$$
V_{l d}=V_{c s}\left(\frac{L}{2}+l\right)\left(\frac{P_{t}}{V_{a c} \times p f}\right)
$$


Where $V_{l d}$ is the voltage drop due to the lighting load, $V_{c s}$ is the cable voltage drop specification per metre per ampere, $L$ is the length of the radial lighting network from the first lighting column to the last, $l$ is the distance from the control box to the first column and $P_{t}$ is the total lighting load in watts.

$$
C_{p}=\left(\frac{\left(V_{a}-V_{l d}\right)}{\frac{P_{c}}{V_{a c} \times p f} \times V_{c s}}\right)
$$

From (2) the maximum distance from the lighting control box in metres that a charger $C_{p}$ with power $P_{c}$ can be positioned without violating the allowable voltage drop $V_{a}$ can be determined.

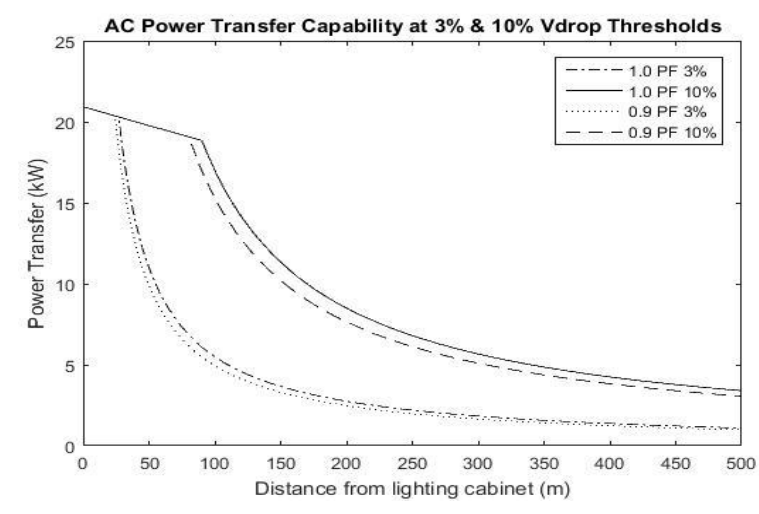

Fig. 2: Power transfer capability of lighting cable based on $3 \%$ and $10 \%$ voltage drops with unity and 0.9 power factors.

From Fig. 2 it can be seen that the main limitation for AC electric vehicle chargers installed on the existing street lighting network is the power transfer distance. A mode-1 $(3.7 \mathrm{~kW})$ charger can operate up to a distance of approximately $150 \mathrm{~m}$ from the lighting control cabinet without violating a $3 \%$ voltage drop, however a mode-2 $(7.4 \mathrm{~kW})$ charger should be within $75 \mathrm{~m}$ of the cabinet to maintain this voltage drop standard. This assumes, however, that only one charger at a time can operate on each radial lighting network. Therefore, a lighting network with multiple charging points requires a control system that will sequentially charge vehicles based on their priority level and the maximum allowable power flow while remaining within voltage drop and protection standards. This could be achieved using a local central controller, a virtual web-based central controller or distributed control between the charging units.

\subsection{Protection}

IEC 60364 standardises the existing protection solutions for low voltage electrical installations. It is of utmost importance that any adaptions to the lighting network remain in accordance with the protection standards, considering the number of Exposed Conductive Parts (ECPs) and the close interaction with the public.
Although rare, insulation failures do occur in lighting network cables [18]. This requires a robust earthing and protection system that can quickly detect and isolate any faults. In [18] the authors carefully compare the available earthing and protection strategies for street lighting networks. In the UK, the most common earthing arrangements are the TN-S or TNC-S systems [12], this involves a dedicated earth core within the lighting cable which is earthed at the lighting control cabinet or distribution transformer. Such earthing arrangements allow the use of Residual Current Devices (RCDs) to detect current leakages and protect against electric shocks caused by indirect contact.

The majority of existing street lighting networks are normally protected by a common Feeder Protection Device (FPD). FPD is based on a simple overcurrent unidirectional technique to protect against faults on the street lighting cables [18]. Adding EV charging points and/or other active devices such as energy storage to the street lighting networks may introduce new protection and safety challenges. Such devices can still provide reverse (transient or steady state) fault currents for upstream faults but this may not be strong enough to operate the main FPD. Each EV charging point will also require a dedicated protection device to avoid tripping the entire lighting network due to a localised charging point fault.

\subsection{Energy Efficiency}

In order to make a complete comparison between a DC lighting and charging network and an AC system, the LED lighting array and EV charging efficiency should be considered as part of the overall feasibility analysis. The development of AC/DC LED drivers, on-board vehicle power converters and off-board fast chargers are evolving rapidly with new topologies and efficiency improvements reported regularly [19][20].

A standard LED lighting array installed on a lighting column requires an AC/DC power converter to drive the native DC lighting diodes. Fairchild reports a $90 \%$ design efficiency for their 150W AC/DC LED driver [21]. With respect to EV charging, field research on the efficiency of mode-1 $(3.7 \mathrm{~kW})$ and mode- $2(7.4 \mathrm{~kW})$ charging units demonstrated efficiencies of $83.8 \%$ and $89.4 \%$ respectively [22]. The efficiency of these trials refers to the energy transferred from the grid to the battery. Therefore, the connection of EV charging points to the public AC lighting network should be of the mode-2 type in order to maintain higher efficiencies.

\section{DC Lighting Network \& Charging System}

This section considers the potential for converting existing street lighting networks to DC distribution in order to provide increased power and locational flexibility for EV charging points on the lighting network. DC distribution systems are in an early stage of development for land based power systems however they have been used extensively in aerospace 
applications and are now being closely examined for use in commercial marine vessels [23].

\subsection{Voltage Selection}

There is no established method to defining the voltage level for a DC distribution system however, the following physical constraints have been considered in determining a suitable voltage level for a DC lighting and charging network:

Cable specifications: The cable in this scenario has a corecore voltage rating of $600 \mathrm{~V}$ AC. Cable voltage ratings are provided as RMS values and therefore the cable insulation can sustain a constant $600 \mathrm{~V}$ DC voltage level with transient peaks up to $840 \mathrm{~V}$.

Peak AC voltage: The lighting cable voltage currently experiences a peak voltage of $326 \mathrm{~V}$ AC. Therefore, a DC voltage close to the existing $\mathrm{AC}$ operating voltage would minimise any accelerated ageing effects [11].

EV charging voltages: DC charging station voltages range from 200-500V DC [24].

Battery charging voltages: Most EV batteries require a sustained voltage that is slightly less than the maximum output of DC chargers, 350-400V DC [24].

LED Lighting: The lighting module, on top of the column, should operate with a voltage that is less than $60 \mathrm{~V}$ which is the upper-limit for extra-low voltage DC and is safer to distribute through the lighting column to the LED array [25]. This voltage requires a buck DC/DC converter, which introduces additional costs and losses.

Existing standards: Industrial organisations such as Emerge Alliance and the European Telecommunications Standards Institute (ETSI) have proposed 380-400V DC standard for datacentres, commercial buildings and telecoms [26]. This standard uses a $\pm 190 \mathrm{~V}$ bi-polar distribution system with an earthed middle point which ensures a distribution voltage that is $200 \mathrm{~V}$ or less. DC voltages up to $200 \mathrm{~V}$ can provide a comparable safety margin as for $250 \mathrm{~V}$ AC according to recommendations in IEC 60479 [27].

Taking these features into consideration, this section assumes a distribution voltage of either $400 \mathrm{~V}$ DC uni-polar or $\pm 200 \mathrm{~V}$ DC bi-polar which is sufficient to enable charging of batteries and provides a $10 \%$ voltage drop contingency. Vendors are beginning to produce $380 \mathrm{~V}-400 \mathrm{~V}$ DC standard products, thanks in part to the burgeoning solar P.V. market, and therefore the implementation of DC lighting and charging networks becomes more cost effective at this voltage level.

\subsection{Distribution Configuration}

Fig. 3 illustrates four different DC distribution topologies that could be used to deliver $400 \mathrm{~V}$ DC to EV charging points located on the lighting network. Each topology labelled (1) to
(4), has slightly different operational characteristics and performance advantages. However, the preferred DC distribution topology must be selected with safety as the primary consideration and power delivery as a secondary priority.

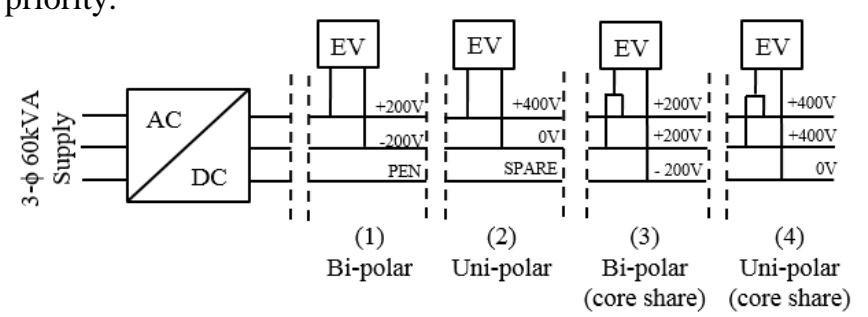

Fig. 3: Suitable DC distribution topologies given a 3-core, $16 \mathrm{~mm}^{2}$ lighting network cable.

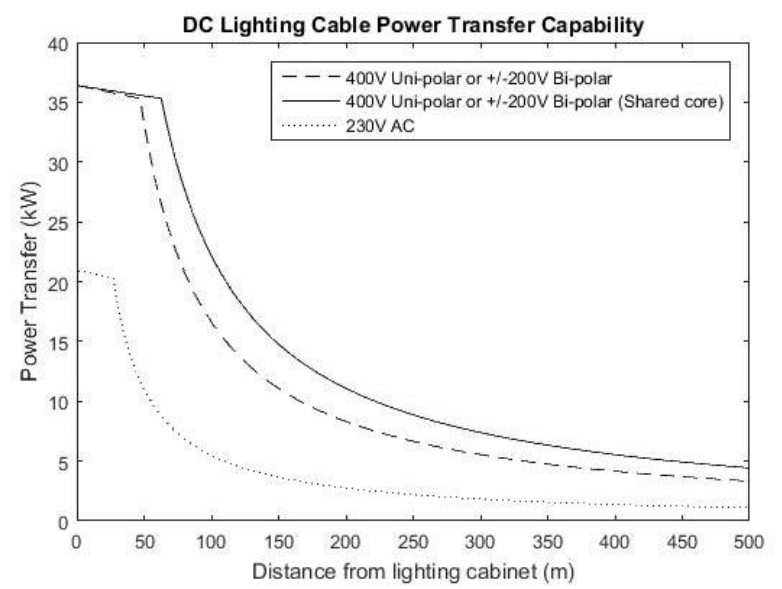

Fig. 4: Power transfer capabilities for different DC distribution configurations with a voltage drop limitation of $3 \%$.

From Fig. 4 it is clear that all DC topologies offer an improvement in power transfer capability compared to AC distribution. In Fig. 3 the $\pm 200 \mathrm{~V}$ bi-polar (labelled 1) and $400 \mathrm{~V}$ uni-polar (2) configurations possess the same power transfer capability, however, the $200 \mathrm{~V}$ system is more closely aligned with the existing $230 \mathrm{~V}$ AC voltage and presents a safer distribution voltage level.

The 'shared-core' system presented in labels 3 and 4 of Fig. 3 offers the highest power delivery over the longest distance by sharing the current between two cores and combining the current on the return core, this reduces the per unit cable voltage drop by $25 \%$ to $2.1 \mathrm{mV} / \mathrm{A} / \mathrm{m}$ as opposed to $2.8 \mathrm{mV} / \mathrm{A} / \mathrm{m}$. The disadvantage of this solution is the lack of a Protective Earth (PE) which means the common TN-S earthing system cannot be used.

This paper considers the $\pm 200 \mathrm{~V}$ DC system to be the optimum solution, where power delivery is slightly compromised but voltage is lower and a spare core remains for dedicated earthing and/or optional communication between the centralised AC/DC converter and the charging points. From Fig. 4 it is clear that this solution (dashed line) can provide almost three times the power delivery compared 
to the $230 \mathrm{~V}$ AC solution (dotted line) at $100 \mathrm{~m}$ from the lighting control cabinet.

\subsection{Protection \& Grounding}

Ensuring user safety in the event of a fault on the network is of paramount importance. In the U.K., existing street lighting networks conform to a $\mathrm{TN}$ earthing arrangement with a maximum disconnection time of 5 seconds according to BS7671. The primary protection concern related to this application is the touch voltage on metallic lighting columns.

Both IT and TN protection systems have been trialled for DC distribution networks. According to [28] the earth isolated IT system offers the fastest touch voltage reduction during a fault compared to a TN system in cases where earth has a high resistivity. However, the IT system requires the use of insulating monitoring devices (IMDs) at the converter end to detect failure of the system insulation, which adds additional cost. In addition, according to BS7671, IT earthing is only specified for extra-low voltage DC, therefore a TN-S earthing arrangement is proposed in this paper where the spare core in the $\pm 200 \mathrm{~V}$ DC system can be used as the common earth, which is the same function in existing AC distribution systems. However, before a DC distribution system can be safely deployed specific standards on the DC fault clearance times should be defined and the operational characteristics of existing DC RCD protection devices confirmed in a controlled environment.

\subsection{Efficiency of DC Lighting \& Charging Network}

On a DC lighting network, as envisaged in this paper, all power must pass through a centralised AC/DC converter at the point of coupling with the main AC grid, this DC voltage must then be stepped down at each lighting column to a suitable level to drive the LED array.

From field trials, [29] reports the full-load efficiency of a fast DC charger to be $92.6 \%$ but this reduces to $83 \%$ when loading conditions fall below $10 \%$ of rated capacity. For the DC/DC buck conversion stage, it is likely a $200 \mathrm{~V}: 48 \mathrm{~V}$ step down converter will be required, this necessitates a buck converter with $97 \%$ efficiency in order to match the conversion efficiency of an AC/DC LED driver when the central DC converter is operating at full load. Under part-load operating conditions, it is likely that the lighting energy efficiency will be at least $10 \%$ less than the AC lighting system. A solution to the lower lighting efficiency is to implement a smaller AC/DC converter in parallel with the main DC charger, the network controller can then switch between converters depending on the demand for power from the network.

\subsection{Network Topology and Charging Control}

Fig. 5 presents a possible system diagram for the conversion of an AC street lighting network to a DC lighting and charging network. A centralised charging converter connects the DC network to the main AC grid with a 3-ph $60 \mathrm{kVA}$ supply at the existing lighting control cabinet. A single distributed EV charging pillar is shown connected across the \pm 200 V DC cables with a main circuit breaker controlling power flow to the EV charging plug. The central converter may consist of a large EV converter and a smaller lighting converter in order to optimise the power efficiency during periods when only lighting is required or alternatively a collection of modular power converters can be used to efficiently regulate the power flow on the network depending on the demand for power.

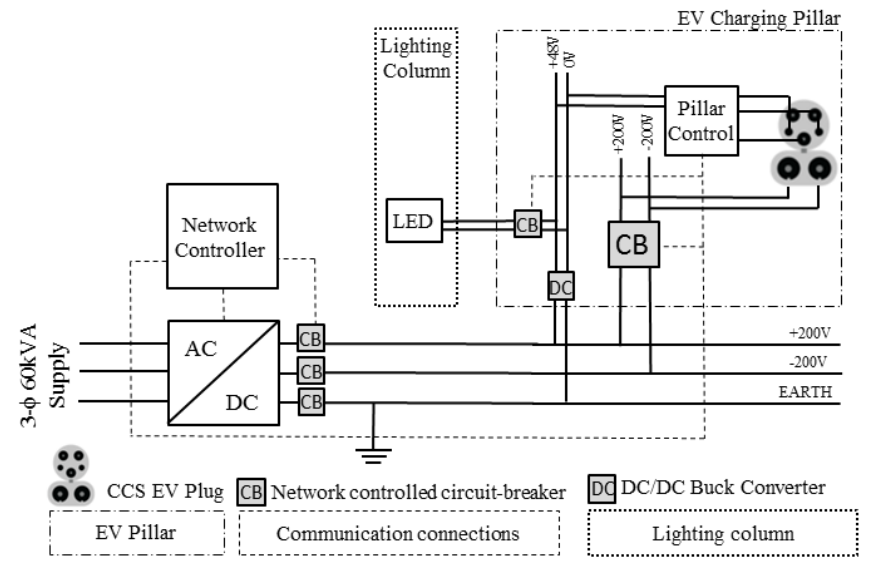

Fig. 5: System diagram of network and a charging pillar with a Combined Charging System (CCS) plug.

The system utilises a pillar controller, which is responsible for maintaining serial communication with the vehicle during charging and for operating the local circuit breaker to start and end the charging process. In this configuration, a central controller maintains a priority list of vehicles and communicates to each pillar controller when it is safe to begin charging the connected EV but this could equally be achieved using a distributed control system.

\section{Conclusion}

This paper has considered the integration of EV charging points on the existing street lighting network and it has introduced the concept of a DC Lighting and Charging network to increase the power transfer capability of the lighting cables in order to enable faster charging of EVs at a higher energy efficiency than AC.

The paper has concluded that a mode- $2 \mathrm{AC}$ charger is more efficient than a mode- 1 charger and it can be positioned up to $75 \mathrm{~m}$ from the lighting control cabinet without violating the $3 \%$ voltage drop standard for the network. For both AC and DC networks, a control system is required to ensure sequential charging of connected EVs to maintain power quality and to avoid overloading of the lighting network. 
The DC charging and lighting system can transfer the same mode-2 power level $(7.4 \mathrm{~kW})$ up to $350 \mathrm{~m}$ within existing voltage drop standards. This allows for greater flexibility in siting connection points on the lighting network. The efficiency of the LED lighting is not expected to increase under DC distribution due to low buck-converter efficiencies however, fast DC EV charging systems are currently 3-5\% more efficient than AC charging systems.

The use of DC distribution for lighting and charging networks requires additional power converter testing and protection validation before implementing a public trial network. The selection of the centralised AC/DC converter and the lighting column DC/DC buck converter is central to the efficient operation of the network. The use of standard DC circuit breakers in conjunction with converter power control should be evaluated and the performance of the network assessed under faulted conditions.

\section{Acknowledgements}

This work has been supported through the EPSRC Centre for Doctoral Training in Future Power Networks and Smart Grids (EP/L015471/1) with industry support from Rolls-Royce plc.

\section{References}

[1] T. Kaipia et al., "Application of low voltage DCdistribution system-a techno-economical study," 19th Int. Conf. Exhib. Electr. Distrib. (CIRED 2007), no. 0464, pp. 21-24, 2007.

[2] Direct Current B.V, "The First DC Smart Grid for Public Lighting," 2014. [Online]. Available: http://www.directcurrent.eu/en/news/newsarchive/112-first-dc-smart-grid-for-public-lighting. [Accessed: 15-Feb-2016].

[3] N. DeMattia, "Future Mobility Solutions: Light and Charge," 2016. [Online]. Available: http://www.bmwblog.com/2016/01/05/future-

mobility-solutions-light-and-charge/. [Accessed: 07Jul-2016].

[4] G. Edwards, "Turning streetlights into charging points," 2015. [Online]. Available: http://www.carplus.org.uk/wp-

content/uploads/2015/12/3.-Greg-Edwards-

Streetlight-charge-point-trial.pdf. [Accessed: 07-Jul2016].

[5] G. C. Council, "Road Lighting Design Brief (Addendum to Roads Development Guide )," no. July, pp. 1-6, 2012.

[6] Green Investment Bank, "Low energy streetlighting: making the switch," no. February, 2014.

[7] Zap-Map, "Charging Point Statistics 2016," 2016. [Online]. Available: https://www.zapmap.com/statistics/. [Accessed: 15-Jun-2016].

[8] International Energy Agency, "Global EV Outlook 2016 Beyond one million electric cars,” 2016.

[9] Office for Low Emissions Vehicle, "The Plug-in Vehicle Infrastructure Strategy,” 2011.
[10] J. Bates and D. Leibling, "Spaced Out Perspectives on parking policy," no. July, pp. 1-118, 2012.

[11] D. Antoniou et al., "DC utilization of existing LVAC distribution cables," 2013 IEEE Electr. Insul. Conf. EIC 2013, pp. 518-522, 2013.

[12] B. 7430:2011, "BSI Standards Publication Code of practice for protective earthing of," no. 1, 2011.

[13] Scottish Power Energy Networks, "Framework for Design \& Planning of LV Housing Developments, Including U/G Networks and Associated HV/LV S/S," no. May, pp. 1-32, 2013.

[14] National Measurement Office, "Guidance on Unmetered Supply Regulations,” vol. 2001, no. March, pp. 1-20, 2014.

[15] S. Gul et al., "Energy-Efficient Intelligent Street Lighting System using Traffic-Adaptive Control," IEEE Sens. J., vol. 16, no. 13, pp. 1-9, 2016.

[16] Telensa, "Telensa PLANet: Public Lighting Active Network." [Online]. Available: http://www.telensa.com/smart-lighting/. [Accessed: 07-Jul-2016].

[17] The Institution of Engineering and Technology, Requirements for Electrical Installations. 2008.

[18] G. Parise et al., "Electrical safety of street light systems," IEEE Trans. Power Deliv., vol. 26, no. 3, pp. 1952-1959, 2011.

[19] R. Xu, "Research on a High-Efficiency LED Driving Circuit Based on Buck Topology," Circuits Syst., vol. 02, no. 04, pp. 352-357, 2011.

[20] J. Lu et al., "An Indirect Matrix Converter based 97 $\%$-efficiency On-board Level 2 Battery Charger Using E-mode GaN HEMTs," Welcome to 3rd IEEE Work. Wide Bandgap Power Devices Appl., vol. T11.8011, pp. 351-358, 2015.

[21] Fairchild Semiconductor, “AN-9738 Design Guideline on 150W Power Supply for LED Street Lighting Design Using FL7930B and FAN7621S," pp. 1-25, 2011.

[22] J. Sears et al., "A comparison of electric vehicle Level 1 and Level 2 charging efficiency," 2014 IEEE Conf. Technol. Sustain. SusTech 2014, pp. 255-258, 2015.

[23] ABB, "The step forward Onboard DC Grid," 2014.

[24] Hydro Quebec, "Electric Vehicle Charging Stations Technical Installation Guide 2nd Edition," no. August, pp. 1-52, 2015.

[25] IET, Code of Practice for Low \& Extra Low Voltage Direct Current Power Distribution in Buildings. 2015.

[26] European Telecommunication Standards Institute, "ETSI EN 300 132-3-1," vol. 1, pp. 1-31, 2011.

[27] IEC TC64, Effects of current on human beings and livestock - Part 4: Effects of lightning strokes, no. October 2006. 2011

[28] P. Salonen et al., "Protection scheme for an LVDC distribution system," no. 0891, pp. 1-4, 2009.

[29] A. Genovese et al., "On the energy efficiency of quick DC vehicle battery charging," EVS28 Int. Electr. Veh. Symp. Exhib., pp. 1-7, 2015. 